Article

\title{
Using Small-Scale Adaptation Actions to Address the Food Crisis in the Horn of Africa: Going beyond Food Aid and Cash Transfers
}

\author{
Richard Munang * and Johnson N. Nkem \\ Climate Change Adaptation and Development Initiative (CC DARE), United Nations Development \\ Programme (UNDP) and United Nations Environment Programme (UNEP), P.O. Box 30552-00100 \\ Nairobi, Kenya; E-Mail: Johnson.Nkem@undp.org
}

* Author to whom correspondence should be addressed; E-Mail: Richard.Munang@unep.org; Tel.: +254207625727; Fax: +254207624249.

Received: 21 July 2011; in revised form: 29 August 2011 / Accepted: 30 August 2011 /

Published: 15 September 2011

\begin{abstract}
The countries Kenya, Uganda, Somalia, Ethiopia and Djibouti are facing the worst food crisis of the 21 st century as a result of devastating droughts. The crisis is causing starvation and leading to a lack of access to clean water and sanitation for over 12 million people. Not only are the direct drought effects endured now by the population, but they have weakened response capacity and created diminished prospects of ever achieving future water and food security. Over the coming decades, temperatures in this region will continue to rise and rainfall patterns will change. This will create major problems for food production and availability. Thus, building resilience in communities is indispensable as we adapt our farming systems to the challenges of climate change. This will require practical solutions that can build on processes involving adaptation to climate change. The lessons learned from the UN-led project in Uganda, demonstrate the value of small scale innovative interventions, carried out using democratic approaches to help support adaptation to climate change whilst progressing to achieve food security and chart a new Path to eliminate hunger. These lessons should be our guiding vision as we address the current droughts plaguing the Horn of East Africa and elsewhere.
\end{abstract}

Keywords: climate change adaptation; small scale solutions; food security 


\section{Introduction}

The spectre of world hunger looms ever larger as the global population fast approaches nine billion [1,2], especially in the least developed nations. Today more than a billion of the planet's nearly seven billion people live on less than a dollar per day. With the surge in population and the continuous food shortages, these numbers will only increase. Food prices soared in 2008 and again, recently, in 2011. The cost of several staple foods reached unprecedented levels making it difficult for millions of poor households to fulfil their basic food needs. This has, in many cases, led to increased public anxiety, social tension and distress. All in all, the consequences of the rise in food prices have demonstrated that the world's food systems (Food systems refer to the chain of activities connecting food production, processing, distribution and access, consumption and waste management as well as all the associated supporting and regulatory institutions and activities) are not responding adequately to increased demand and limited supplies in ways that favor the interests of poor people. Inequities in food systems are exacerbated by the impact of climate change, droughts and land degradation on agricultural production and food systems [3]. Factors like the current drought affecting about ten million people in Djibouti, Ethiopia, Kenya, Somalia and Uganda have increased risks of food insecurity for smallholder households, affecting their ability to operate profitably and meet their households' food needs. Given that hunger and poverty are concentrated in rural areas, targeting local food systems represents the single biggest opportunity to increase food production, boost food security, and reduce vulnerability. Local food systems have potential to provide livelihoods, occupation, employment and socio-cultural meaning to a very large share of the world's active working population.

Sub-Saharan Africa is currently the most food-insecure region in the world and eighty five per cent of its population lives in the rural areas with many of them small share farmers facing numerous challenges, including climate change, resource scarcity, government neglect and severe ecological degradation. The impact of these challenges is better understood by the farmers themselves but without community-led innovations, farmers and citizens are unable to develop their own forums for discussions. Lack of these forums can also indirectly uphold traditional gender roles because women innovators are not recognized for their work thus hindering the achievement of food sovereignty. We need a radical shift away from the existing top-down and increasingly corporate-controlled approaches to a democratic approach which devolves more responsibility and decision-making power to farmers, indigenous peoples, food workers, consumers and citizens. This democratic approach ensures farmers and ordinary citizens directly decide what kind of an agricultural research and practice they want - for whom, how it should be done, where and by whom, and what are the likely consequences - rather than those approaches that are offered from mainstream research institutions and policy think tanks. It is therefore urgent to re-examine the resilience and impacts of democratic interventions and their contribution to local and global food systems.

The current drought crisis in the Horn of Africa offers a window of opportunity to refocus the world's attention on food, agriculture, and rural areas and to re-establish food security as a global priority. Efforts to ensure the existence of food systems that provide adequate food security for those who need it most - like the rural poor in the horn of Africa — need to have available a broader range of solutions. The purpose of this paper is to demonstrate the value of small scale innovative interventions, 
carried out using democratic approaches in Uganda to help support adaptation to climate change whilst progressing towards achieving food security and charting a new path to eliminate hunger.

\section{Key Messages}

- The present paradigm of intensive crop production cannot meet the challenges of the new millennium. Investing in a new food production model using small-scale fiscal stimulus that mobilizes the untapped potential of local people is imperative for unleashing a food secured society.

- Small scale democratic processes can provide a mechanism to find sustainable solutions to the problem of food security, and such processes have the potential to spread benefits much more evenly across communities of farmers and consumers alike.

- A "new agricultural development paradigm" premised on more and better investments in African food production, putting smallholders at the center of actions is urgently needed.

- A new approach for a 'sustainable' vision premise on democratic small scale actions, which reduces tillage, protects the soil surface, and alternates cereals with soil-enriching legumes works for all.

- With proper planning, transparent resource management; innovative food security policies; and integrative agriculture inputs and outputs, the Horn of Africa's food crisis will be turned into an opportunity.

\section{Old Approaches-Revolutions Afoot?}

Nearly half a century after the Green Revolution, a large share of people are still chronically hungry in some parts of the world. Some of the approaches to combating hunger have not been effective. Past attempts have focused on large industrial farms which need a lot of fossil fuels, chemical fertilizers, and large machinery [4]. Mechanized large scale farms practice monoculture that depletes the land of nutrients and encourages certain diseases, weeds and pests which are dealt with by an array of pesticides and herbicides. This type of agriculture is extremely harsh on the environment. As petroleum and food prices soar, and droughts intensifies, and as unfair trade agreements persist, the challenge of reducing hunger will prove that much more difficult. Still, the current drought crisis in the Horn of Africa offers a window of opportunity for refocusing the world's attention on food, agriculture, and rural areas and for re-establishing food security as a global priority. We must therefore shift our focus to a food system that nourishes the planet without compromising the soils, crop diversity, and fresh water on which we all depend.

\section{New Approaches: Small Scale Democratic Solutions}

Ensuring food systems provide adequate food security for those who need it most-like the rural poor in sub Saharan Africa-needs a broader range of solutions. Previous practice has demonstrated that small scale actions can provide just the right framework for catalyzing transformative change on a larger scale. The advantage of small scale approaches is that they can be quickly implemented with local capacity, have short turnover period, and could potentially stimulate spontaneous self-uptake, 
rather than supply-driven uptakes. Small-scale approaches are characterized by engagement of local users, keeping the implementation process simple, and making them more efficient, effective, equitable and democratic than past top-down practices. The democratic process can lead to diverse forms of co-inquiry based on specialist and non-specialist knowledge, an expansion of the horizontal networks for autonomous learning and action, and more transparent oversight [5]. Small scale solutions are characterized by:

- Democratization of the actions and solutions: Citizens who decide which new policy and technical innovations are needed, when, where and under what conditions.

- De-institutionalization of actions for autonomous learning: Knowledge creation by and for the people means taking responsibility for one's own learning process; and addressing issues that relate to people's aspirations and lives.

- Enabling contexts for social learning and action: Professionals all have specialist knowledge that can usefully feed citizen deliberations and more inclusive forms of participation that strengthen civil society.

- Demonstration of ownership: communities exercise effective leadership over their adaptation/development policies and strategies and coordinate development/adaptation actions.

\section{Drawing on Small Scale Democratic Solutions in Uganda}

In supporting the implementation of adaptation in Uganda's National Adaptation Programme of Action (NAPA), the project 'Adapting to Climate Change through Increased Water and Nutrient Use Efficiency for Increased Crop Productivity and Environmental Health' was undertaken in two districts in Eastern Uganda by the National Agricultural Research Laboratory (NARL) using funds and technical backstopping provided by the Climate Change Adaptation and Development (CC DARE), an initiative jointly implemented by the UN Environment Programme (UNEP) and UN Development Programme (UNDP) for Sub Saharan Africa. The goal of CC DARE is to improve countries' abilities to integrate adaptation into their national development agenda as well as to capitalize on the emerging opportunities from the adaptation action in achieving resilience and sustainability.

Building on the democratic characteristics above, the implementation of the UN-led program was guided by the premise that while we could not prevent rain failure and prolonged dry spells taking their toll on the farming communities, we could help them minimize the painful impacts of these natural hazards. In each of the two districts where the project was implemented, one sub county was selected and out of each sub county 600 farmers were selected to host the demonstrations on maize production under conservation agriculture.

Serving as a showcase of connecting science with policy and practice, the project characterized agro-meteorological climate risks and uncertainties regarding crop production in the country. From this, information was generated about seasonal rainfall characteristics which offer opportunities for exploiting seasonal rainfall distribution to improve/stabilize crop yield through incorporation of seasonal characteristics of onset, cessation and length of the crop growing season. This information has helped guide crop substitution and diversification. During the implementation of this project, several adaptation technologies were introduced and demonstrated by several farmers, such as conservation agriculture and integrated nutrient management in maize production. At the district level, district 
officials benefited by gaining knowledge about the impacts of climate change and variability and the available adaptation and mitigation technologies/practices in the region. At the national level, participants in the national workshop including Members of Parliament (MPs) were exposed, for the first time, to empirical data on climate change and variability. They were also exposed to others' experiences and strategies, including grassroots organizations.

These demonstrations have contributed to enhancing capacity and acceptance of such practices by others because not only were they environmentally more sustainable but also farmers managed to retain their harvests demonstrating the resilience of their systems even under the risks and threats presented by climate change.

\section{Additionality of Small Scale Solutions to National and International Food Security Policy}

Lessons learned from the Ugandan CC DARE examples demonstrate that small approaches have potential to trigger other opportunities. The CC DARE program in Uganda showed that using small scale solutions premised on democratic approaches could have modest benefits particularly in terms of uptake by other farmers. All stakeholders, inclusive of district extension officers and leaders, politicians, farmers and scientists were involved in the planning and implementation. Democratic planning helped to bring the district people on-board and to fully own the project. The engagement of citizens in the communities to facilitate the implementation helped to ensure sustainability and up-scaling of technologies.

The project had significant benefits by providing the opportunity for gaining greater insight on climate change and variability scenarios in the country, especially its impacts on agriculture and food security and farmers' coping methods.

The outcomes of the project have contributed to the Ugandan Natural Resource and Environment (ENR) Sector and DSIPs (Development and Strategic Investment Plans) whose goals are to increase sustainable food production by improving agriculture techniques and practices and optimal use of land and water resources which is consistent with the World Food Plan of Action. The outcomes contributed to the Ugandan National Land-use Policy, which aims to fill a gap in integrated land-use planning/management across sectors and among land users/stakeholders; and the draft National Soils Policy, which aims to maintain productivity of land/agro-ecosystems. The project, in modest ways, also contributed to national commitments to the framework of the United Nations Convention on Climate Change (UNFCC) process through effects of better land use and management practices on protecting the hydrological regime.

\section{Ecological Basis of Food Systems: Offshoots of Using Small Scale Actions in Uganda}

Reorienting local food systems towards modes of production that are highly productive with ability to improve the sustainability of agro-ecosystems by creating beneficial biological interactions and synergies among the different components are imperative.

- The actions in Uganda have demonstrated good agronomic practices which are currently taken up by farmers e.g., soil and water conservation, use of inputs such as fertilizers, biological nitrogen fixation by leguminous cover crops, etc. in addition to timely planting at a larger scale 
improved productivity at field level. This has resulted in increased productivity at field level: ensuring food availability.

- Initially where the action took place in Uganda, conventionally preparing an acre of land for planting costs no less than US\$100, however, with conservation agriculture (CA) introduced through the implemented actions only $25 \%$ of that cost is adequate to prepare the land. Beside the monetary savings, such techniques have saved time allowing farmers to engage in other enterprises as well, such as livestock rearing in the country. In tandem, these efforts have helped reduce rural poverty in Uganda. Also besides growing more food, the sustainable approach has decreased the use of chemical fertilizer and pesticides, saving farmers money, reducing pollution and allowing depleted soils to recover.

- The judicious crop rotation piloted was based on a maize-bean-maize-bean cropping system, contributing to improved nutrition because of the carbohydrate/protein outputs

- The demonstrations were hosted by model farmers who have since scaled up their operations; prompted by the successful demonstrations other farmers have picked up the practice

\section{Discussion}

Given the unfortunate occurrence of droughts in the Horn of Africa, practical actions are ever more critical to ensure achieving food security in this region. If the recommendations stated above are taken on board with mutual interest and implemented, famine will recede and climate change will become more manageable. Although there are likely to be severe weather events in the future that we cannot prevent, the CC DARE approach can help stabilize communities and help build biophysical and social resilience. This is vital as it will increase local buffering capacity against droughts, make communities more independent from direct aid, etc., build resilience and improve livelihoods overall. Up-scaling of lessons learnt requires programs with flexible approaches of funding like the CC DARE to help prevent crises like this from happening again. The consequences of not sustaining workable programs like CC DARE and others is that vulnerable communities will continue to depend on external support, rather than develop their own resilience and independence. The benefits of understanding what has previously worked can provide a guiding vision as we proactively address the current crisis. With proper planning, transparent resource management, innovative food security policies, and integrative agriculture inputs and outputs, the horn of Africa's food crisis will be turned into an opportunity.

\section{Conclusions}

Small scale solutions guided by science/research have never been more critical to achieving food security than they are today. New research and new thinking will be indispensable as we adapt our farming systems to the challenges of climate change. Research and pilots that are conducted/ developed through democratic approaches not only better serve farmers working in the most difficult conditions, but they are the only way we can shift towards an agricultural paradigm with sustainability, food security and the prioritization of small food producers at its heart, rather than an agenda which raises aggregate food production in large units serving the global markets. The lessons learned from this project demonstrate that exposing food security solutions to the public by presenting it as a democratic issue, helps counterbalance the influence of vested interests and in leveling the playing 
field in favor of small producers. With transparency and accountability to those whom it is meant to serve, small scale adaptation solutions to food systems could spread their benefits much more evenly across communities of farmers and consumers alike. The lessons learnt demonstrate that the democratization of food security solutions has begun in farmers' fields and must be our guiding vision as we address the current droughts plaguing the Horn of East Africa and elsewhere

\section{Acknowledgments}

The Ministry of Foreign Affairs of Denmark provided the funds for this project. The government and the people of Uganda led the implementation of the project. All views expressed in this article are those of the authors and do not necessarily reflect the views of United Nations or the funding agency.

\section{References and Notes}

1. UNPD. World population prospects, the 2010 Revision. United Nations Population Division (UN DESA): New York, NY, USA, 2011.

2. FAO. How to Feed the World in 2050. Food and Agriculture Organization: Rome, Italy, 2009. Available online: http://www.fao.org/fileadmin/templates/wsfs/docs/expert_paper/How_to_feed_ the_World_2050.pdf (accessed on 19 July 2011).

3. Sian Lewis. Can Small-Scale Farmers Feed the World? Available online: http://www.iied.org (accessed on 27 August 2011).

4. De Schutter, O. Food Commodities Speculation and Food Price Crises. Regulation to reduce the risks of price volatility; Briefing Note 02: New York, NY, USA, September 2010. Available online: http://www.srfood.org/images/stories/pdf/otherdocuments/20102309_briefing_note_02_ en_ok.pdf (accessed on 27 August 2011).

5. Pimbert, M.P.; Boukary, B. Democratizing research for food sovereignty in West Africa. J. Peasant Studi. 2010, 37, 220-226.

(C) 2011 by the authors; licensee MDPI, Basel, Switzerland. This article is an open access article distributed under the terms and conditions of the Creative Commons Attribution license (http://creativecommons.org/licenses/by/3.0/). 